\section{Drying Rates following Priming Affect Temperature Sensitivity of Germination and Longevity of Lettuce Seeds}

\author{
Andrés R. Schwember and Kent J. Bradford ${ }^{1}$ \\ Department of Vegetable Crops, One Shields Avenue, University of California, \\ Davis, CA 95616-8631
}

Additional index words. Lactuca sativa, seed priming, germination, controlled deterioration, headspace volatiles analysis

\begin{abstract}
Seed priming (controlled hydration followed by drying) is used to alleviate high temperature inhibition of germination and improve seedling emergence of lettuce (Lactuca sativa $L_{\text {.) }}$ and other species. However, seed priming can also reduce the longevity of seeds during dry storage. Alternative drying methods [i.e., slow drying or moisture content reduction (MCR) before drying] can extend seed longevity compared to conventional rapid drying procedures after priming. Three postpriming drying treatments were tested on 'Conquistador' and 'Genecorp Green' lettuce seeds: rapid drying, slow drying and MCR $(\mathbf{1 0} \%$ fresh weight loss, then held at $100 \%$ relative humidity $(\mathrm{RH})$ for 6 hours, followed by rapid drying). The effects of the postpriming treatments on seed quality and longevity were compared based upon standard germination tests, germination rates, thermogradient table tests, controlled deterioration (CD) tests, and headspace volatiles analysis. The latter may be correlated with seed longevity as release of volatiles (e.g., acetaldehyde, ethanol) is associated with lipid peroxidation. While neither slow drying nor MCR before drying restored lettuce seed longevity to that of the control (not primed) seeds, the MCR method generally gave better results in both cultivars compared to rapid drying. Among the $\mathrm{CD}$ test conditions used, $50{ }^{\circ} \mathrm{C}$ and $75 \% \mathrm{RH}$ gave the most consistent results for estimating potential longevity. Headspace volatile emissions from both control and primed lettuce seeds were very low and were not well correlated with seed longevity. Alternative postpriming drying regimes can extend seed longevity while retaining the beneficial effects of priming.
\end{abstract}

Seed priming is a technique to improve the germination behavior of seed, inducing faster and more uniform germination over broader temperature ranges and breaking dormancies inherent in certain species (e.g., thermoinhibition of lettuce, Lactuca sativa L.) (McDonald, 1999). During priming, seeds are hydrated to a level below that needed for radicle emergence, allowing pregerminative metabolism to proceed, and then dried to the original moisture content (McDonald, 2000). However, these procedures often result in a reduction of seed longevity in storage compared to nonprimed seed (Chojnowski et al., 1997; Maude et al., 1994; McDonald, 1999; Tarquis and Bradford, 1992).

Postpriming treatments using alternative drying methods (e.g., slow drying or seed moisture content reduction before drying) have extended seed longevity compared to conventional rapid drying methods after priming in species such as celery (Apium graveolens L.) (Coolbear et al., 1991), foxglove (Digitalis

Received for publication 6 Aug. 2004. Accepted for publication 12 Oct. 2004. This research was funded in part by Incotec International B.V., by the Western Regional Seed Physiology Research Group and by CSREES Regional Research Project W-168. We thank Incotec for assistance with the temperature gradient experiments and Seminis Vegetable Seeds for providing the lettuce seeds. Frederick J. Sundstrom and Carlos F. Quiros provided constructive comments on the manuscript.

${ }^{1}$ To whom reprint requests should be addressed; e-mailkjbradford@ucdavis.edu. trockiana) (Bruggink et al., 1999), and tomato (Lycopersicon esculentum Mill.) (Gurusinghe et al., 2002). To evaluate the potential benefits of postpriming treatments to increase the shelf-life of primed lettuce seed, the quality and longevity of primed seeds dried using different methods were analyzed and compared based upon several germination and vigor tests: standard germination test, germination time course tests, thermogradient table test, and controlled deterioration (CD) tests. Emission of volatiles from seeds was also assayed to evaluate its use as a seed aging test (Wilson and McDonald, 1986).

\section{Materials and Methods}

Seeds and priming treatments. Seeds of 'Conquistador' and 'Genecorp Green' lettuce cultivars were obtained from Seminis Vegetable Seeds (Oxnard, Calif.). 'Annie' and 'Red Line' cultivars were also evaluated but did not respond favorably to the priming protocol utilized (data not shown; see Schwember, 2003). 'Conquistador' is a Romaine-type cultivar that can be sensitive to rapid aging; therefore special care is needed in priming and in seed storage. It exhibits a higher upper temperature limit as compared to standard Romaine cultivars even without priming, but priming is still applied to improve emergence uniformity. 'Genecorp Green' is a selection of 'Waldmann's Green', both photo- and thermo- sensitive, but responding favorably to priming. (J.de Vries, Seminis Vegetable Seeds, personal communication).

The same priming procedure was conducted for all the treatments: seeds were osmoprimed in glass bubblers containing an aerated -1.25 MPa solution of PEG 8000 for $24 \mathrm{~h}$ under continuous light. Seeds were then rinsed briefly with water after incubation and surface water was removed by suction in a Buchner funnel. The postpriming treatments were as follows.

Rapid drying. Primed seeds were dried for $4 \mathrm{~h}$ at $32{ }^{\circ} \mathrm{C}$ and $25 \%$ to $30 \%$ relative humidity $(\mathrm{RH})$ in a ventilated oven, then were transferred to a sealed chamber (with internal fan for air circulation) that contained saturated $\mathrm{CaCl}_{2}$ solution to maintain $33 \% \mathrm{RH}$ at $15^{\circ} \mathrm{C}$ for $48^{2} \mathrm{~h}$.

Slow drying. Primed seeds were dried at $20{ }^{\circ} \mathrm{C}$ for $24 \mathrm{~h}$ in a sealed chamber over $5 \%$ w/v glycerol (99\% RH, $-1.4 \mathrm{MPa})$, then were transferred and equilibrated at $33 \% \mathrm{RH}$ and $15^{\circ} \mathrm{C}$ as described above.

Moisture content reduction (MCR). Primed seeds were weighed and spread over germination paper in a fume hood to allow their total fresh weight to decrease by about $10 \%$ (e.g., $10 \mathrm{~g}$ of wet seeds were air-dried until the total weight reached $9 \mathrm{~g}$ ), then were placed on a screen in a sealed chamber over distilled water $(100 \% \mathrm{RH})$ for $6 \mathrm{~h}$ at $20^{\circ} \mathrm{C}$ before subsequent rapid drying and transfer to $33 \% \mathrm{RH}$ at $15^{\circ} \mathrm{C}$ as described above. Seed samples collected at various times were oven-dried at $130{ }^{\circ} \mathrm{C}$ for $1.5 \mathrm{~h}$ and their moisture contents (MC) were determined on a fresh weight basis. The final $\mathrm{MC}$ of seeds following the three postpriming treatments was $5 \%$ to $6 \%$.

Germination tests and seedling evalu- ations. For germination tests, lettuce seeds were plated in $8.8-\mathrm{cm}$-diameter petri dishes wetted with distilled water ( 8 to $9 \mathrm{~mL}$ ). Each dish contained 25 seeds and there were three replicates per treatment. The lettuce seeds were incubated under continuous fluorescent light at $20^{\circ} \mathrm{C}$, and after 5 to $6 \mathrm{~d}$ were scored as normal or abnormal seedlings using the ISTA rules (International Seed Testing Association, 1999). In separate tests under the same conditions, germination (radicle emergence) time courses were evaluated for both cultivars for each treatment.

Thermogradient table test. A temperature gradient ranging from 16 to $18^{\circ} \mathrm{C}$ to 34 to 36 ${ }^{\circ} \mathrm{C}\left(2{ }^{\circ} \mathrm{C}\right.$ increments $)$ with 10 locations and one blotter per location was established using a temperature gradient table (Seed Processing Holland B.V., Enkhuizen, The Netherlands). As each germination location on the thermogradient table spanned $2{ }^{\circ} \mathrm{C}$, the temperature locations are referred to by their midpoints. Thirty-three seeds were distributed over each blotter, and the percentage of normal seedlings per blotter was assessed $72 \mathrm{~h}$ after planting. The results were replicated in three separate experiments.

Controlled deterioration tests (CD tests). Seeds for CD tests were adjusted to higher $\mathrm{MC}$ by incubation over saturated $\mathrm{NaCl}$ solution $(75 \% \mathrm{RH})$ for $48 \mathrm{~h}$ at $2.5{ }^{\circ} \mathrm{C}$ in a sealed over single circular germination blotters 
chamber. The seeds were then sealed in vials and transferred to a controlled environment chamber at $32^{\circ} \mathrm{C}$ or were submerged in a water bath at $50{ }^{\circ} \mathrm{C}$. Samples were removed at various times and germination (normal seedling) tests were subsequently conducted as described previously to assess viability.

Headspace volatiles analysis. The release of volatiles from seeds was assessed as an indication of lipid peroxidation (McDonald, 1999; Wilson and McDonald, 1986) and to determine whether this test could be used as a seed vigor index (Kataki and Taylor, 1995; McDonald, 1999; Zhang etal., 1994; Zhang and Roos, 1997). 'Conquistador' seeds were first placed in four relative humidity chambers that contained saturated $\mathrm{LiCl}(12 \% \mathrm{RH}), \mathrm{Mg}\left(\mathrm{NO}_{3}\right)_{2}$ $(53 \%), \mathrm{NaCl}(75 \% \mathrm{RH})$ solutions or distilled water $(100 \% \mathrm{RH})$ at $15{ }^{\circ} \mathrm{C}$. After $48 \mathrm{~h}$, the seeds were removed from the chambers and put in $10-\mathrm{mL}$ vials sealed with rubber septa that were submerged in a water bath at $50{ }^{\circ} \mathrm{C}$. The headspace of the vials was sampled $(1 \mathrm{~mL})$ after $24 \mathrm{~h}$, and the acetaldehyde and ethanol contents were determined using gas chromatography (GC-14A; Shimadzu Corporation, Kyoto, Japan) through a $3.2 \mathrm{~mm}$ diameter by 1.8-m long stainless steel column packed with 5\% CBWX 20M (Carbograph 1 AW 80/120 mesh) (Alltech). Empty vials were sampled as controls to correct for potential volatile release from the rubber septa.

\section{Results and Discussion}

Moisture content loss rates. 'Conquistador' and 'Genecorp Green' seeds lost water similarly during dehydration following priming (Fig. 1). The rapid drying protocol reduced

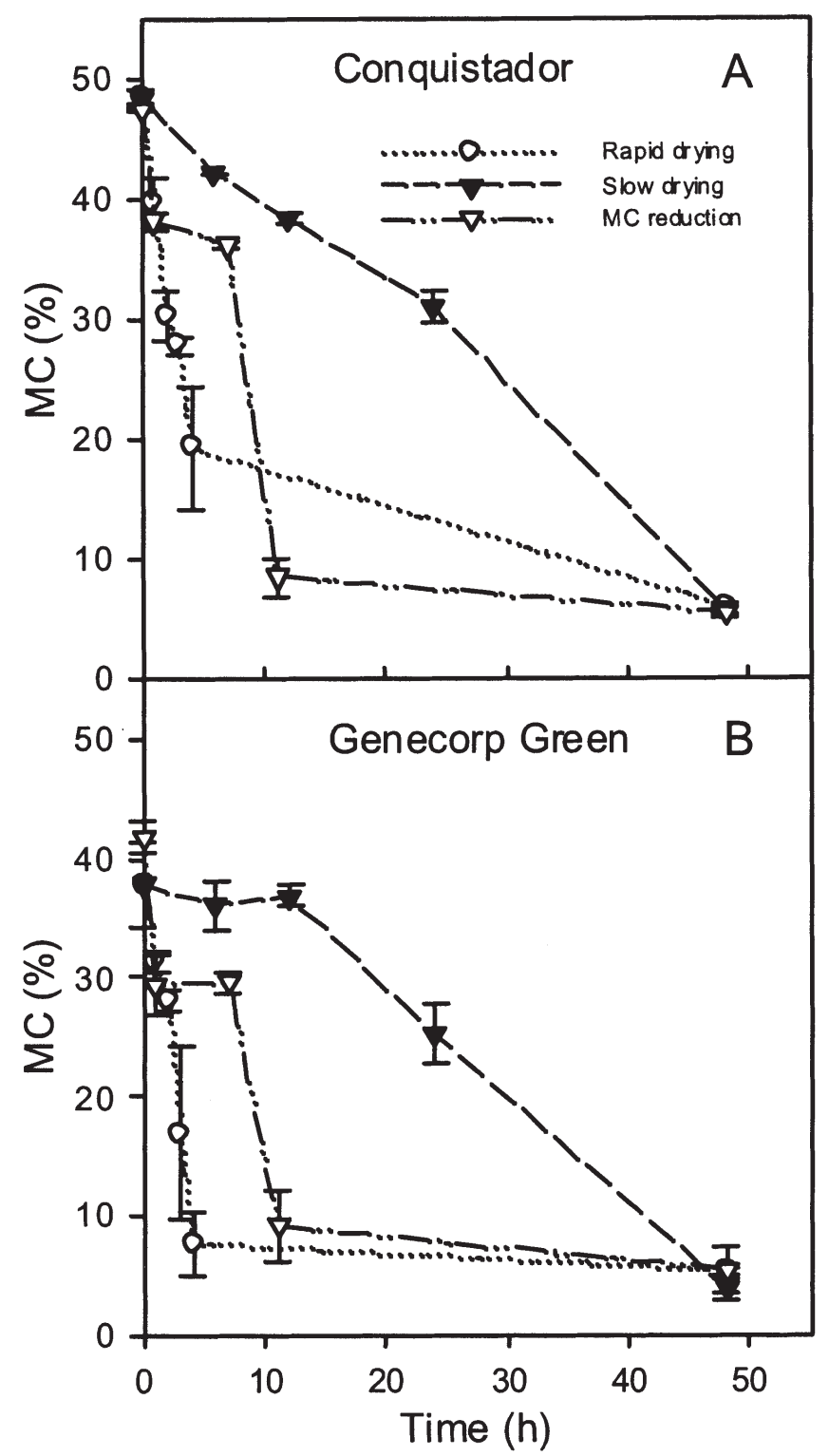

Fig. 1. Moisture content loss kinetics of three postpriming drying regimes. After identical initial priming treatments, 'Conquistador' (A) and 'Genecorp Green' (B) lettuce seeds were rapidly dried, slowly dried or subjected to the MCR protocol and seed moisture contents were measured periodically. Error bars indicate $\pm \operatorname{SE}(\mathrm{n}=3)$. seed MC to below $20 \%$ within $4 \mathrm{~h}$, while this required more than $24 \mathrm{~h}$ under the slow drying conditions. For the MCR protocol, seed MC remained between $30 \%$ to $40 \%$ for $6 \mathrm{~h}$ before rapid drying. Final MC were between 5\% to $6 \%$ for seeds of all treatments after equilibration at $33 \% \mathrm{RH}$.

Germination rates. Priming followed by the slow drying and MCR treatments accelerated the germination rates of seeds of both cultivars, while priming followed by rapid drying did not hasten germination significantly in either cultivar relative to the control seeds (Fig. 2). Rapid drying (or the warm temperature associated with it) apparently negated the germination advancement expected from the priming treatment.

Thermogradient table test. Before priming,

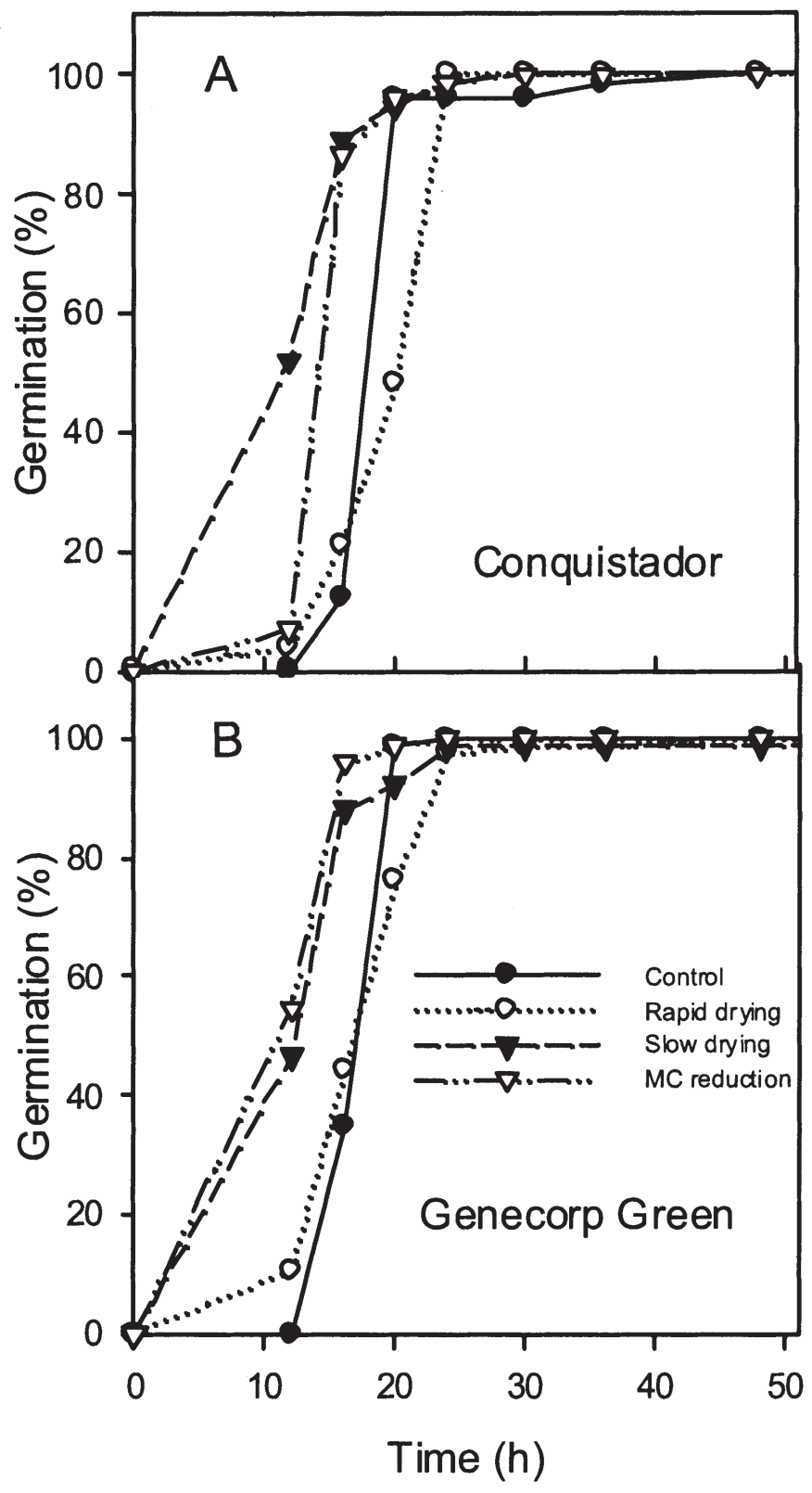

Fig. 2. Germination (radicle emergence) time courses of 'Conquistador' (A) and 'Genecorp Green' (B) lettuce seeds after priming and drying at different rates. Data are means of three replicates. Error bars are omitted for clarity, but the maximum standard errors $(\mathrm{n}=3)$ were $9 \%$ ('Conquistador') to $14 \%$ ('Genecorp Green') when germination was $<50 \%$, and decreased thereafter. 
'Conquistador' seeds germinated well up to $29{ }^{\circ} \mathrm{C}$, then germination dropped to $<5 \%$ at $31{ }^{\circ} \mathrm{C}$. In contrast, germination of control 'Genecorp Green' seeds began to be inhibited at $21^{\circ} \mathrm{C}$ and was $<5 \%$ at $29^{\circ} \mathrm{C}$. This is consistent with expectations for these two cultivars, with 'Genecorp Green' exhibiting greater thermosensitivity than 'Conquistador'. For 'Conquistador' seeds, the percentage of normal seedlings was significantly greater in the slowly dried and MCR treatments compared to the rapidly dried and control seeds at temperatures above $29^{\circ} \mathrm{C}$ (Fig. 3A). The slowly dried and MCR treatments did not differ significantly at the highest temperature range (about $30 \%$ of normal seedlings). 'Genecorp Green' seeds responded favorably to priming, with an increase in the median temperature for germination (the

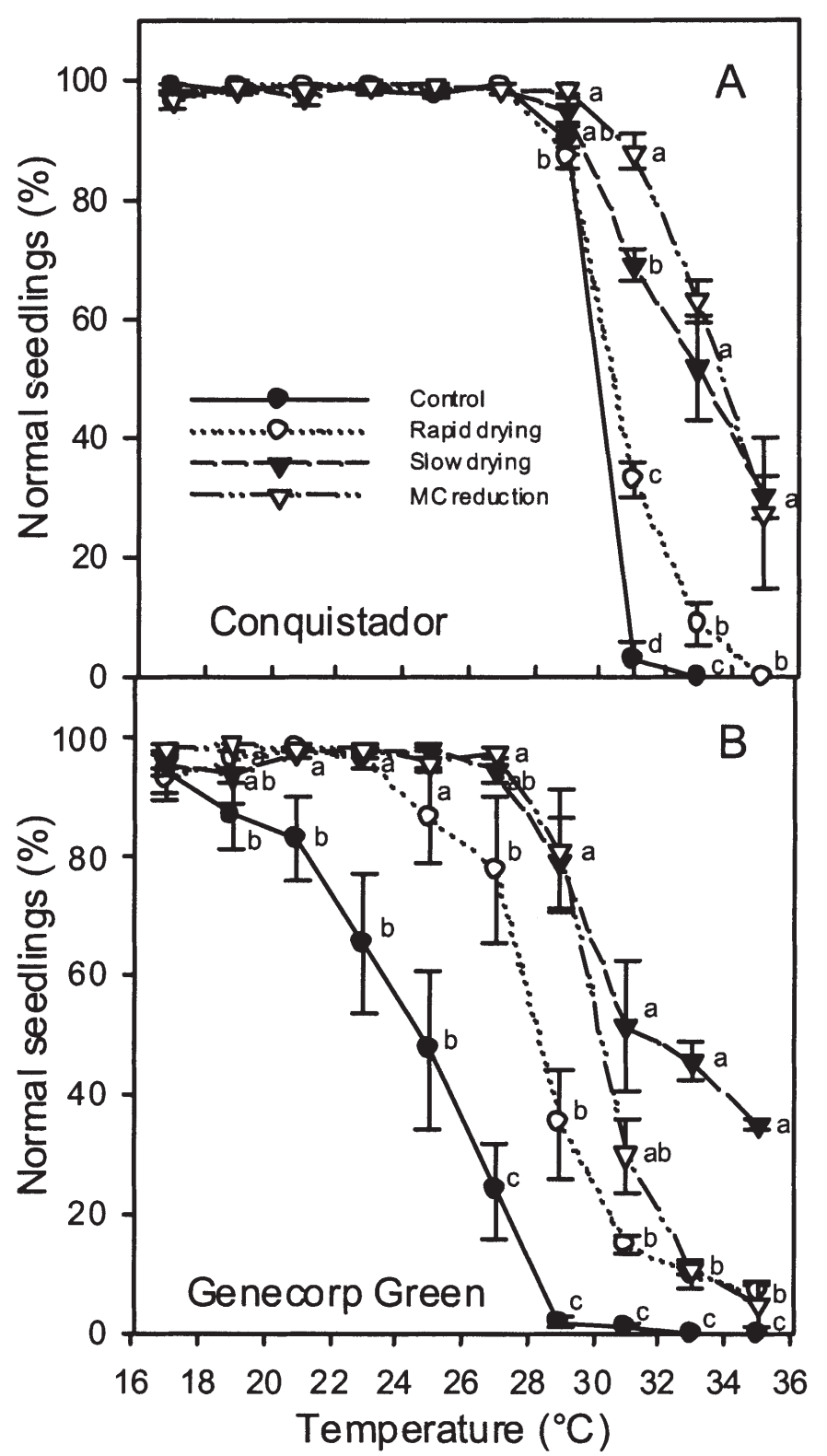

Fig. 3. Temperature sensitivity of germination of 'Conquistador' (A) and 'Genecorp Green' (B) lettuce seeds in a thermogradient table test at 17 to $35{ }^{\circ} \mathrm{C}$. The percentage of normal seedlings was assessed three days after sowing. At each temperature, analysis of variance and Duncan's multiple range test were used to identify significant mean separations (means followed by the same letter at each temperature do not differ at the $5 \%$ level). Error bars indicate $\pm \operatorname{SE}(n=3)$. temperature at which germination is reduced to $50 \%$ ) of $4{ }^{\circ} \mathrm{C}$ with rapid drying and up to $8{ }^{\circ} \mathrm{C}$ for the slow drying treatment following priming (Fig. 3B).At $31{ }^{\circ} \mathrm{C}$ and higher, the slow drying procedure was statistically superior to the other treatments. In both cultivars, slow drying and MCR after priming resulted in greater high temperature tolerance during germination than did rapid drying (Fig. 3). The response to priming was more evident for 'Genecorp Green'seeds than for 'Conquistador' seeds

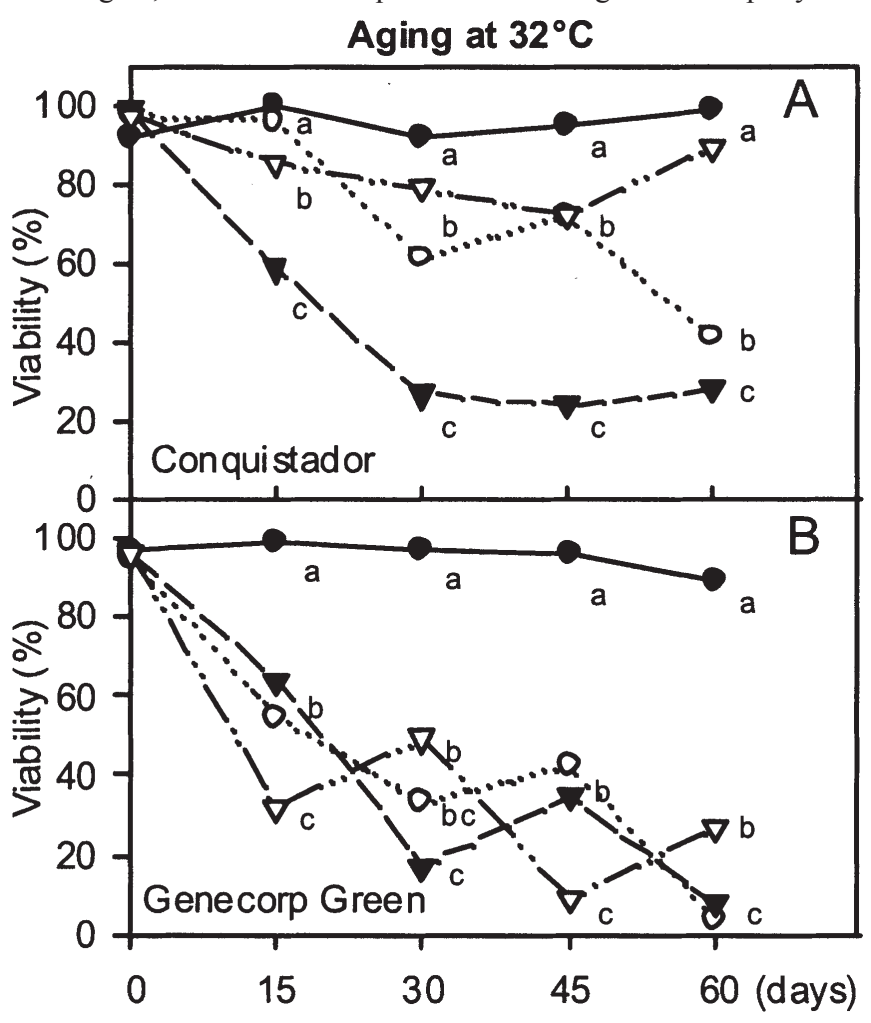

Aging at $50^{\circ} \mathrm{C}$

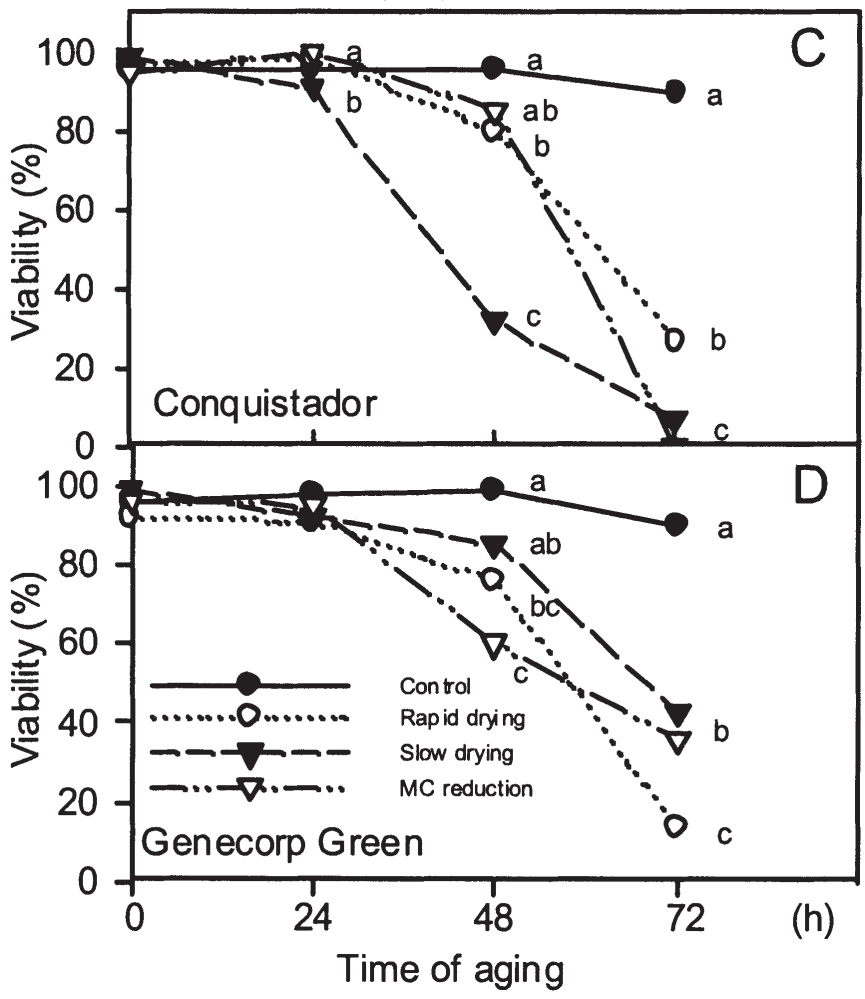

Fig. 4. Controlled deterioration (CD) tests of lettuce seeds subjected to different postpriming drying regimes. The $\mathrm{CD}$ tests were performed at 32 (A and B) and $50{ }^{\circ} \mathrm{C}(\mathbf{C}$ and $\mathbf{D})$ and $75 \% \mathrm{RH}$ on 'Conquistador' (A and $\mathbf{C}$ ) and 'Genecorp Green' (B and D) lettuce seeds. At each sampling time, analysis of variance and Duncan's multiple range test were used to identify significant mean separations (means followed by the same letter at each time do not differ at the $5 \%$ level). 


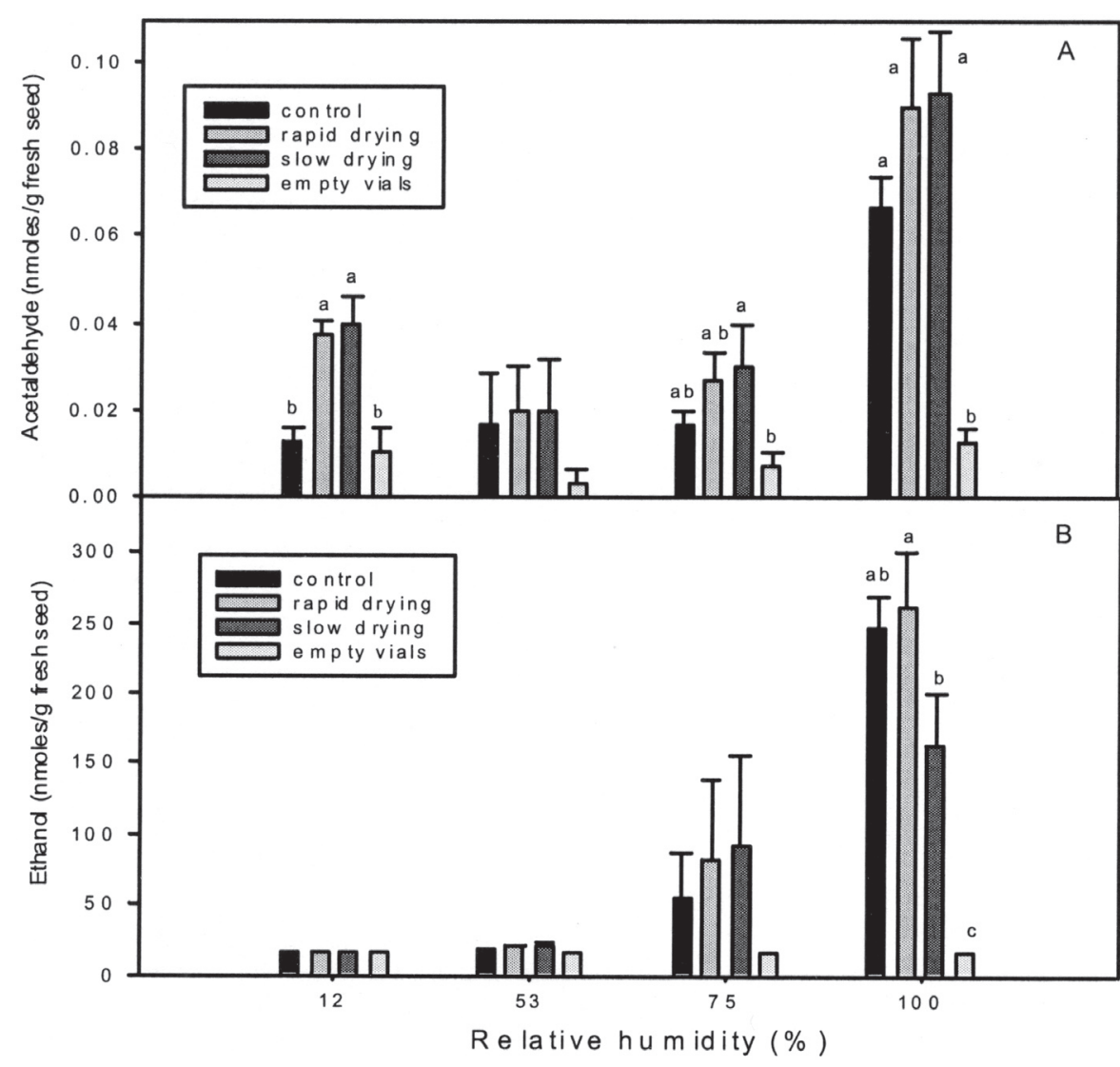

Fig. 5. Release of volatiles from primed lettuce seeds aged at different relative humidities. The amounts of acetaldehyde (A) and ethanol (B) (nmol $\cdot \mathrm{g}^{-1}$ fresh seed) in the headspace of sealed vials containing ' Conquistador' lettuce seeds after $24 \mathrm{~h}$ at $50{ }^{\circ} \mathrm{C}$ in $12 \%, 53 \%, 75 \%$, or $100 \% \mathrm{RH}$. At each $\mathrm{RH}$, analysis of variance and Duncan's multiple range test were used to identify significant mean separations (means followed by the same letter at each humidity do not differ at the $5 \%$ level). Error bars indicate \pm SE $(n=3)$.

lowing slow drying, followed by the rapid drying and MCR treatments (Fig. 4A). In 'Genecorp Green' seeds aged at $32{ }^{\circ} \mathrm{C}$, the three postpriming treatments all resulted in more rapid deterioration, with little difference among them (Fig. 4B). In the $50{ }^{\circ} \mathrm{C} \mathrm{CD}$ test, the rapidly dried and MCR seeds of 'Conquistador' again exhibited greater longevity than the slowly dried seeds (Fig. 4C). However, the viability of all three postpriming treatments was low compared to the control after $72 \mathrm{~h}$ of aging. For 'Genecorp Green' seeds aged at $50^{\circ} \mathrm{C}$, no consistent differences in viability were evident among the postpriming treatments, which all died more rapidly than the untreated seeds (Fig. 4D). Tarquis and Bradford (1992) also found no significant difference in longevity (at $82.5 \%$ $\mathrm{RH}$ and $40{ }^{\circ} \mathrm{C}$ ) of 'Empire' lettuce seeds due to rapid or slow drying after priming.

An erratic pattern of seed viability loss was evident at $32^{\circ} \mathrm{C}$ (Fig. 4A and B) that was not present at $50{ }^{\circ} \mathrm{C}$ (Fig. $4 \mathrm{C}$ and D). Originally, $32^{\circ} \mathrm{C}$ was chosen as an alternative aging temperature in order to more closely simulate actual storage conditions. However, at $75 \% \mathrm{RH}$, this temperature may permit metabolic processes resulting in imposition of secondary dormancy that can be mistaken for loss of viability. At $50{ }^{\circ} \mathrm{C}$, the temperature may be too high for dormancy to be imposed before aging occurs. Consequently, the $50{ }^{\circ} \mathrm{C}$ test can be regarded as a more reliable $\mathrm{CD}$ test because it only encompasses the aging effect, whereas the 32
${ }^{\circ} \mathrm{C} \mathrm{CD}$ tests may be confounded by induction of dormancy.

Headspace analysis. The release of acetaldehyde from 'Conquistador' seeds was measured after $24 \mathrm{~h}$ at $50{ }^{\circ} \mathrm{C}$ under different RHs (Fig. 5A). Significant differences in acetaldehyde release were identified at $12 \%$, $75 \%$ and $100 \%$ RH. At the lowest RH, seeds dried both rapidly and slowly produced larger quantities of acetaldehyde than the control seeds and the empty vials. At $100 \%$ RH, seeds of both drying treatments and the control released greater amounts of acetaldehyde than the empty vials. Overall, the production of acetaldehyde was very low, and increased markedly at $100 \% \mathrm{RH}$.

Ethanol emission was also detected from 'Conquistador' seeds after $24 \mathrm{~h}$ at $50{ }^{\circ} \mathrm{C}$ under different RHs (Fig. 5B). Significant differences among the treatments occurred exclusively at $100 \% \mathrm{RH}$, where ethanol production was promoted. At this RH, seeds from the rapid drying treatment generated greater concentrations of ethanol than did slowly dried seeds, although neither of these differed significantly from the control. 'Conquistador' seeds did not show a directly proportional relationship between ethanol emission and viability since control at about $250 \mathrm{nmol} \cdot \mathrm{g}^{-1}$ fresh seed (with $95 \%$ and $60 \%$ of viability, respectively), compared to slowly dried seeds that generated 150 nmoles of ethanol $/ \mathrm{g}$ fresh seed and only showed $20 \%$ of and rapidly dried seeds both produced ethanol viability after 24 h of aging (Schwember, 2003). In conclusion, although acetaldehyde and ethanol emissions increased as RH increased, there were no strong correlations between the amount of volatile released and seed viability.

Generally, the alternative drying procedures (MCR and slow drying treatments) outperformed the conventional rapid drying method in terms of priming effects (broadening the germination temperature range and speeding germination rates). However, the postpriming treatments in this study were unable to extend lettuce seed longevity to match that of the untreated seeds, although the MCR treatment was often better than the rapid drying treatment. Further work will be needed to identify postpriming protocols that can significantly extend the longevity of lettuce seeds.

\section{Literature Cited}

Bruggink, G.T., J.J.J. Ooms, and P. Van der Toorn. 1999. Induction of longevity in primed seeds. Seed Sci. Res. 9:49-53.

Chojnowski, M., F. Corbineau, and D. Come. 1997. Physiological and biochemical changes induced in sunflower seeds by osmopriming and subsequent drying, storage and aging. Seed Sci. Res. 7:323-331.

Coolbear, P., P.E. Toledo, and U. Setagoses. 1991. Effects of temperature of pre-sowing hydration treatment and subsequent drying rates on the germination performance of celery seed. N.Z. J. Crop Hort. Sci. 19:9-14.

Gurusinghe, S., A.L. Powell, and K.J. Bradford. 2002. Enhanced expression of $\mathrm{BiP}$ is associated with treatments that extend storage longevity of primed tomato seeds. J. Amer. Soc. Hort. Sci. 127:528-534

Hay, F.R. and R.J. Probert. 1995. Seed maturity and the effects of different drying conditions on desiccation tolerance and seed longevity in foxglove (Digitalis purpurea L.). Ann. Bot. 76:639-647.

International Seed Testing Association. 1999. International rules for seed testing. Seed Sci.Technol. 27:(Suppl.)

Kataki, P. and A.G. Taylor. 1995. Respiratory byproduct-ethanol:An indicator of lettuce and sweet corn seed quality. HortScience 30:870.

Maude, R.B., R.L.K. Drew, D. Gray, W. Bujalski, and A.W. Nienow. 1994. The effect of storage on the germination and seedling abnormalities of leek seeds primed and dried by different methods. Seed Sci. Technol. 22:299-311.

McDonald, M.B. 1999. Seed deterioration: Physiology, repair and assessment. Seed Sci. Technol. 27:177-237.

McDonald, M.B. 2000. Seed priming, p. 287-325. In: M. Black and J.D. Bewley (eds.). Seed technology and its biological basis. CRC Press, Boca Raton, Fla.

Schwember, A.R. 2003. Effects of postpriming treatments on potential longevity of lettuce seeds. MS thesis. Univ. Calif., Davis.

Tarquis, A.M. and K.J. Bradford. 1992. Prehydration and priming treatments that advance germination also increase the rate of deterioration of lettuce seeds. J. Expt. Bot. 43:307-317.

Wilson,D.O. and M.B. McDonald. 1986. Aconvenient volatile aldehyde assay for measuring seed vigour. Seed Sci. Technol. 14:259-268.

Zhang, M., Y.Maeda, Y.Furihata, Y.Nakamura, andY. Esashi. 1994.Amechanism of seed deterioration in relation to the volatile compounds evoked by dry seeds themselves. Seed Sci. Res. 4:49-56.

Zhang, M. and E.E. Roos. 1997. Using seed volatiles as a possible indicator for seed deterioration during storage. HortScience 32:526. 